Bolm Inst. oceanogr., S Paulo, 25:55-76, 1976

\title{
SOBRE A MIGRAÇÃO VERTICAL DIÁRIA DO PLÂNCTON AO LARGO DE SANTOS, ESTADO DE SÃO PAULO, BRASIL
}

GLŌRIA SOARES MOREIRA

Instituto de Biologia Marinha da Universidade de São Paulo e Departamento de Fisiologia Geral, Instituto de Biociências da Universidade de São Paulo

\section{SYNOPS IS}

Several stations were occupied off the coast of Santos, with the purpose of studying the diurnal vertical migration of plankton. The results showed that in the region, the patterns of migration of net plankton are quite diversified and they cannot be related to different seasons or oceanographic parameters.

\section{INTRODUÇÃO}

As primeiras referências sobre a migração vertical diāria do plâncton são de Cuvier (1817). Desde então, crescente número de pesquisadores tem-se dedicado ao estudo do problema.

As grandes expedições oceanogräficas do último século, particularmente a do "Challenger" (1873-1876), tiveram como uma de suas finalidades o estudo da migração vertical diäria. Murray (1885) foi o primeiro a informar-se da grande extensão do fenômeno, referindo que animais vivendo em profundidades maiores que $200 \mathrm{~m}$ durante o dia, sobem até a superfície durante a noite. Trabalhos mais recentes estão revelando ser muito maior essa amplitude. 
Waterman et al. (1939) demonstraram migrações de vários decápodes, misidáceos, eufasiáceos e anfípodes, a partir de $1.000 \mathrm{~m}$ de profundidade. Birstein \& Chindonova, 1958 (in Vinogradov, 1970), estudando os häbitos alimentares de misidáceos, demonstraram que populações vivendo em profundidades ao redor de $4.000 \mathrm{~m}$ sobem à superfície para se alimentar.

A migração vertical diāria é hoje considerada um dos aspectos mais impressionantes e característicos do plâncton marinho. Sua natureza geral foi confirmada por autores trabalhando em diferentes áreas, como por exemplo Hardy \& Gunther (1936) no Antärtico, Bigelow \& Sears (1939) no Atlântico norte ocidental, Bogorov (1946) no Ārtico, King \& Hida (1954, 1957) no Pacífico equatorial, Hure (1955) no mar Adriático, Légand (1958) no Pacífico sul, Bogorov \& Vinogradov, em 1960, no Pacífico central (in Banse, 1964) e McAllister (1961) no golfo do Alasca. Foi melhor estudada nos crustáceos, porém dificilmente existe um filo com representantes no zooplâncton marinho que não possua espécies com movimentos migratōrios diārios.

Vários autores vêm tentando explicar as causas e a significação do fenômeno. O mais recente sumário da extensa bibliografia sobre o assunto é dado em Vinogradov (1970). Verificou-se que não somente diferentes espécies têm comportamento diferente, mas também animais em diferentes estágios de desenvolvimento e condições fisiológicas. Além disso, machos e fêmeas de uma mesma espécie podem comportar-se diversamente. Diferenças sazonais foram observadas numa mesma espécie (Russe1, 1928). Copépodes do gênero Acartia, em laboratório, continuam realizando migrações durante certo tempo mesmo em ausência de luz (Ester1y, 1917). Enright \& Hamner (1967) demonstraram que rítmos internos são de importância para a migração vertical de várias espécies de crustáceos.

Russe1 (1925-1934), baseado em numerosas observações, considerou ser a luz o fator mais importante relacionado à migração diāria. A maioria dos autores concorda com Russe1 (Kikuchi, 1930; Cushing, 1951). Desconhece-se, no entretanto, se a luz atua por sua absoluta intensidade ou por variações de intensidade (Clarke, 1933; Johnson, 1938). Desconhece-se, também, se ela provoca uma resposta direta, ou se age indiretamente, por influência sobre outros fatores importantes (temperatura, alimento, etc.). 
Clarke (op. cit.), no golfo do Maine, evidenciou o efeito da temperatura no movimento migratōrio, demonstrando constituir a termoclina uma barreira para a migração do copépode Metridia Zucens. Seus indivíduos foram coletados durante o dia entre $51-60 \mathrm{~m}$. À noite, ao invés de subirem até a superfície, migraram somente até a região da termoclina (10-20 m). Já uma outra espécie, Centropages typicus, não realiza movimento descendente, tendo sido coletada apenas acima da termoclina. Moore \& Corwin (1956) e Moore \& Bauer (1960) expressaram estatisticamente a variação da distribuição vertical diäria de espécies de sifonóforos e copépodes computando a iluminação, temperatura e pressão.

Worthington (1931) lançou a hipótese de que como a maioria das diatomáceas e microplâncton vivem nas camadas superficiais, o zooplâncton migraria para essas camadas durante a noite visando a obtenção de alimento. Durante o dia, migrariam para o fundo a fim de evitarem os efeitos adversos das altas intensidades luminosas.

A significação da migração vertical diāria em termos de valor adaptativo à vida planctônica tem sido, tambēm, muito discutida. Hardy (1956) enfatiza sua importância na distribuição horizontal. Como geralmente as camadas de água superiores se movem com mais velocidade que as inferiores, às vêzes mesmo em direções opostas, o movimento dos planctontes nessas diferentes camadas determinaria com que fossem carregados para grandes distâncias, assegurando assim uma maior área de distribuição. Somar-se-ia, ainda, que o movimento para as camadas superficiais asseguraria extensivas condições de alimentação. David (1961) emitiu a hipótese de que a principal função da migração diāria seria a mistura de populações vivendo em condições ecológicas diferentes, facilitando o fluxo de gens através dos indivíduos que as compõem.

O transporte descendente de matéria orgânica pelos animais migrantes constitui uma das grandes fontes de alimento para os animais de profundidade (Vinogradov, 1962, in Banse, 1964). Senão mais importante, é que o "turnover" da matéria orgânica nos oceanos, para ser entendido, necessita do conhecimento de qual fração da população penetra e deixa, em seus movimentos de migração vertical diāria, as camadas superficiais de água (Banse, 1964). 
Informações sobre a migração vertical diāria no Atlântico sul ocidental são escassas.

Os trabalhos anteriores sobre o zooplâncton ao largo do Brasil meridional, em sua maioria, referem-se à descrição de espécies e sua distribuição em relação às diferentes massas de água presentes na região (Vannucci, 1957, 1963; Almeida Prado, 1961; Björnberg, 1963; Forneris, 1965; Tavares, 1967, etc.). Björnberg \& Wilbur (1968) estudaram em laboratōrio a migração vertical diāria de algumas espécies de copépodes, e a influência de corantes xantênicos nessa migração.

0 objetivo deste trabalho foi o estudo da migração vertical diäria do plâncton por intermédio de coletas sucessivas, feitas ao largo de Santos, durante três anos. Na região, gradientes de temperatura e salinidade ocorrem freqüentemente, assim como termoclinas e haloclinas mais ou menos pronunciadas. A presença de diferentes massas de água nas vārias profundidades jā foi indicada por Emílsson $(1959,1961)$. No presente trabalho, relacionou-se o movimento migratório do plâncton com os parâmetros acima mencionados, isto é, salinidade, temperatura e massas de água. Almeida Prado (1968) e Björnberg (1969) estudaram, respectivamente, a migração vertical diäria de quetognatos e copépodes através de algumas destas amostras de plâncton. Estudo sobre o comportamento de medusas foi publicado por Moreira (1973).

\section{MATERIAL E MÉTODOS}

Para este estudo foram ocupadas värias estações ao largo de Santos, com duração de 24 horas cada uma, durante os anos de 1960, 1961 e 1962. As coordenadas geográficas do local são $24^{\circ} 16,8^{\prime} \mathrm{S}-46^{\circ} 00,4^{\prime} \mathrm{W}$; distância da costa, 20 milhas; profundidade 1ocal: $50 \mathrm{~m}$.

Em cada estação tomaram-se os dados hidrográficos usuais, juntamente com coletas horizontais de plâncton. Para as coletas de plâncton foi usada uma 
rede "standard" de fechamento, construída com nylon no 3, arrastada durante 15 min em três profundidades diferentes, sendo uma vez em superfície $(0 \mathrm{~m})$, outra à meia-água $(20-25 \mathrm{~m})$ e outra próxima ao fundo $(45 \mathrm{~m})$. Essas coletas foram repetidas a cada 4 horas.

No laboratório, mediu-se o volume total de plâncton por deslocamento. Nas figuras e tabelas, os valores (horas) foram estandartizados a intervalos regulares e referem-se sempre ao início das coletas. As datas referem-se sempre ao dia de início da estação.

\section{O MEIO AMBIENTE}

0 exame dos dados de temperatura e salinidades indicou que quatro diferentes massas de água estiveram presentes na região, em diferentes épocas e profundidades.

De acordo com Emílsson $(1959,1961)$ estas massas de água podem ser classificadas em:

1 - Água tropical de salinidade maior que $36 \%$ e temperatura maior que $20^{\circ} \mathrm{C}$, transportada para o sul pela corrente do Brasil.

2 - Água subtropical de salinidade 35-36 \% e temperatura variando de 10-20 $\mathrm{C}$. Na região estudada, esta água foi denominada por alguns autores (Vannucci, 1957; Björnberg, 1963) de água de plataforma e água de plataforma de profundidade. Prefiro manter o nome de subtropical, apesar dela fluir, no caso, sobre a plataforma, porque mantem os limites de variação de temperatura e salinidade da água subtropical e nela ocorrem as espécies de água fria, típicas da água subtropical profunda, que se move em direção norte sob a água tropical. 
3 - Água costeira de salinidade menor que $35 \%$ e temperatura maior que $20^{\circ} \mathrm{C}$, formada próxima à costa por aquecimento local e mistura de água doce proveniente do continente.

4 - Água da plataforma, com salinidade de 35-36\% e temperatura maior que $20^{\circ} \mathrm{C}$ formada sobre a plataforma, por mistura de águas tropical, subtropical e costeira e influenciada por aquecimento local.

\section{RESULTADOS}

0 volume total de plâncton foi relativamente abundante em todas as estações, exceto nas realizadas em abril de 1960 e julho de 1961 (Tabela).

A maior densidade $\left(2,47 \mathrm{cc} / \mathrm{m}^{3}\right)$ foi observada a 23 de setembro de 1960, a $45 \mathrm{~m}$ de profundidade, ao meio dia $\left(19,8^{\circ} \mathrm{C}\right.$ de temperatura, $36,04 \%$ de salinidade). As demais coletas na meșma data foram ricas em plâncton, notandose quantidade sensivelmente grande de diatomáceas nas amostras de fundo e não nas de superfície e meia-água.

A menor densidade $\left(0,01 \mathrm{cc} / \mathrm{m}^{3}\right)$ foi obtida na amostra de $45 \mathrm{~m}(20: 00 \mathrm{~h})$, no dia 8 de abril de 1960 , em temperatura de $16,4^{\circ} \mathrm{C}$ e salinidade de $35,66 \%$. As demais coletas na mesma data, assim como as de 7 de julho de 1961, também foram pobres em plâncton.

A ocorrência de maiores densidades de plâncton nas estações de setembro a janeiro e menores densidades nas estações de abril e julho, parece estar relacionada a uma variação sazonal, em que interferem numerosos fatores, além dos aqui mencionados.

Tundisi et al. (1969), estudando os mangues estuarinos de Cananéia, mostraram um bem marcado ciclo sazonal no "standing-stock" de fito e zooplâncton, com um pico no verão e um mínimo no inverno. Os resultados aqui obtidos sugerem fortemente que, no local deste estudo, a curva de variação sazonal corresponde à de Cananéia, indicando certa concordância no aumento ou diminuição da densidade planctônica entre as regiões estuarinas internas (Cananéia) e as de águas rasas, próximas à costa (Santos). 
TABELA - Densidade do volume de plâncton $\left(\mathrm{cc} / \mathrm{m}^{3}\right)$

\begin{tabular}{|c|c|c|c|c|c|c|c|c|}
\hline Data* & Prof. (m) & 00 & 04 & 08 & 12 & 16 & 20 & 24 \\
\hline \multirow[t]{2}{*}{$08 / 04 / 1960$} & $\begin{array}{c}0 \\
20-25 \\
45\end{array}$ & $\begin{array}{l}0,09 \\
0,11 \\
0,04\end{array}$ & $\begin{array}{l}0,15 \\
0,09 \\
0,09\end{array}$ & $\begin{array}{l}0,02 \\
0,05 \\
0,13\end{array}$ & $\begin{array}{l}0,03 \\
0,05 \\
0,20\end{array}$ & $\begin{array}{l}0,04 \\
0,08 \\
0,04\end{array}$ & $\begin{array}{l}0,07 \\
0,04 \\
0,01\end{array}$ & $\begin{array}{l}0,04 \\
0,02 \\
0,12\end{array}$ \\
\hline & Prof. (m) & 12 & 16 & 20 & 24 & 04 & 08 & 12 \\
\hline \multirow[t]{2}{*}{$22 / 09 / 1960$} & $\begin{array}{c}0 \\
20-25 \\
45\end{array}$ & $\begin{array}{l}0,44 \\
0,80 \\
1,77\end{array}$ & $\begin{array}{l}0,29 \\
0,71 \\
1,55\end{array}$ & $\begin{array}{l}0,13 \\
0,24 \\
0,24\end{array}$ & $\begin{array}{l}0,66 \\
0,88 \\
0,22\end{array}$ & $\begin{array}{l}0,22 \\
0,55 \\
0,13\end{array}$ & $\begin{array}{l}0,22 \\
0,84 \\
1,11\end{array}$ & $\begin{array}{l}0,49 \\
0,22 \\
2,47\end{array}$ \\
\hline & Prof. (m) & 16 & 20 & 24 & 04 & 08 & 12 & 16 \\
\hline \multirow[t]{2}{*}{$21 / 03 / 1961$} & $\begin{array}{c}0 \\
20-25 \\
45\end{array}$ & $\begin{array}{l}0,62 \\
0,29 \\
0,78\end{array}$ & $\begin{array}{l}0,62 \\
0,64 \\
0,22\end{array}$ & $\begin{array}{l}0,49 \\
0,62 \\
0,07\end{array}$ & $\begin{array}{l}0,53 \\
0,51 \\
0,42\end{array}$ & $\begin{array}{l}0,13 \\
0,15 \\
0,20\end{array}$ & $\begin{array}{l}0,15 \\
0,15 \\
0,35\end{array}$ & $\begin{array}{l}0,40 \\
0,15 \\
0,27\end{array}$ \\
\hline & $\begin{array}{ll} & \text { Tempo (h) } \\
\text { Prof. (m) } & \end{array}$ & 12 & 16 & 20 & 24 & 04 & 08 & 12 \\
\hline \multirow[t]{2}{*}{$06 / 07 / 1961$} & $\begin{array}{c}0 \\
20-25 \\
45 \\
\end{array}$ & $\begin{array}{l}0,04 \\
0,13 \\
0,13\end{array}$ & $\begin{array}{l}0,09 \\
0,08 \\
0,07\end{array}$ & $\begin{array}{l}0,13 \\
0,22 \\
0,09\end{array}$ & $\begin{array}{l}0,12 \\
0,20 \\
0,13\end{array}$ & $\begin{array}{l}0,08 \\
0,21 \\
0,12\end{array}$ & $\begin{array}{l}0,09 \\
0,17 \\
0,13\end{array}$ & $\begin{array}{l}0,07 \\
0,08 \\
0,11\end{array}$ \\
\hline & Prof. (m) & 08 & 12 & 16 & 20 & 24 & 04 & 08 \\
\hline \multirow[t]{2}{*}{$07 / 11 / 1961$} & $\begin{array}{c}0 \\
20-25 \\
45 \\
\end{array}$ & $\begin{array}{l}0,22 \\
0,84 \\
0,73\end{array}$ & $\begin{array}{l}0,33 \\
0,55 \\
0,18 \\
\end{array}$ & $\begin{array}{l}0,22 \\
0,33 \\
0,67\end{array}$ & $\begin{array}{l}0,22 \\
1,00 \\
0,62 \\
\end{array}$ & $\begin{array}{l}0,07 \\
0,49 \\
1,53 \\
\end{array}$ & $\begin{array}{l}0,07 \\
0,69 \\
1,09 \\
\end{array}$ & $\begin{array}{l}0,15 \\
0,47 \\
0,55 \\
\end{array}$ \\
\hline & Prof. (m) & 16 & 20 & 24 & 04 & 08 & 12 & 16 \\
\hline \multirow[t]{2}{*}{$09 / 01 / 1962$} & $\begin{array}{c}0 \\
20-25 \\
45\end{array}$ & $\begin{array}{l}0,37 \\
0,78 \\
1,42\end{array}$ & $\begin{array}{l}1,87 \\
0,89 \\
0,37\end{array}$ & $\begin{array}{l}1,44 \\
0,67 \\
0,67\end{array}$ & $\begin{array}{l}0,37 \\
0,55 \\
0,67\end{array}$ & $\begin{array}{l}0,11 \\
0,44 \\
1,67\end{array}$ & $\begin{array}{l}0,15 \\
1,11 \\
1,44\end{array}$ & $\begin{array}{l}0,26 \\
0,67 \\
1,44\end{array}$ \\
\hline & Prof. (m) & 00 & 04 & 08 & 12 & 16 & 20 & 24 \\
\hline $28 / 11 / 1962$ & $\begin{array}{c}0 \\
20-25 \\
45\end{array}$ & $\begin{array}{l}0,51 \\
0,53 \\
0,53\end{array}$ & $\begin{array}{l}0,55 \\
0,55 \\
0,46\end{array}$ & $\begin{array}{l}0,38 \\
0,53 \\
0,44\end{array}$ & $\begin{array}{l}0,29 \\
0,38 \\
0,58\end{array}$ & $\begin{array}{l}0,59 \\
0,42 \\
0,44\end{array}$ & $\begin{array}{l}0,55 \\
0,55 \\
0,58\end{array}$ & $\begin{array}{l}0,62 \\
0,98 \\
0,47\end{array}$ \\
\hline
\end{tabular}


Em todas as estações, exceto numa (7 de novembro de 1961) ocorreu migração vertical típica (Figs 1-7).

Em 8 de abril de 1960 (Fig. 1), a migração realizou-se desde o fundo até a superfície, sendo que a descida do plâncton para as camadas inferiores deve ter se iniciado após as 04:00 horas, coincidindo com as horas do amanhecer. Às 08:00 h, a grande maioria estava no fundo, repetindo-se esta condição às $12: 00 \mathrm{~h}$. Às $16: 00 \mathrm{~h}$, embora as condições de luz ainda estivessem bastante intensas, a maioria do plâncton jā se encontrava à meia-água. Às $20: 00 \mathrm{~h}$, o plâncton tinha alcançado as camadas superiores, restando $10 \%$ no fundo. Nas coletas de $24: 00 \mathrm{~h}$ a grande maioria aparece no fundo, o que sugere uma rápida descida dos animais que estavam na superfície, fato incomum a esta hora. A explicação dessa ocorrência não pôde ser relacionada com os parâmetros medidos.

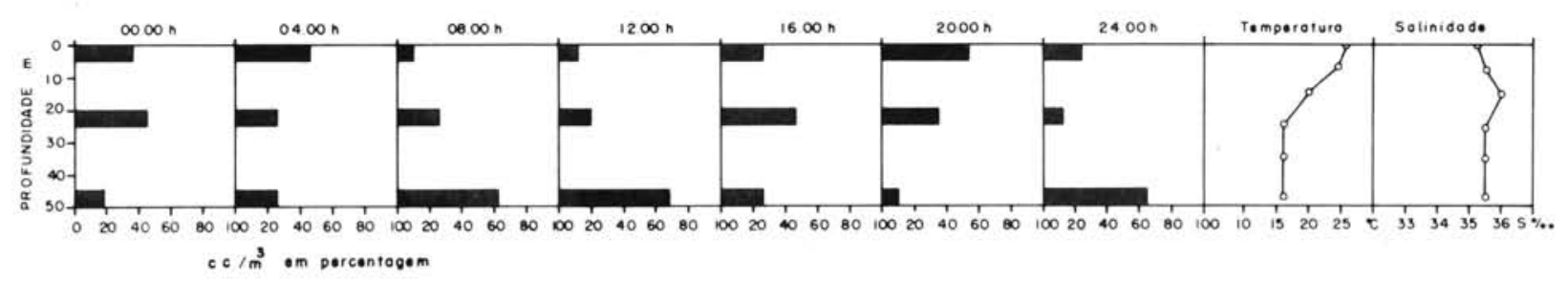

Fig. 1 - Variação na distribuição do plâncton, em percentagem. $(08 / 04 / 60)$.

A presença de uma marcada termoclina entre 7 e $25 \mathrm{~m}$ não interferiu na migração. Os limites de temperatura foram 16,4 a $26,0^{\circ} \mathrm{C}$. A salinidade manteve-se uniforme, ao redor de $35 \%$, porém na profundidade de $15 \mathrm{~m}$ foram encontradas salinidades de $36 \%$ até um pouco acima.

Relacionando-se os dados de temperatura e salinidade pode-se concluir que duas massas de água estavam presentes na região: águas subtropicais (abaixo de $15 \mathrm{~m}$ ) e águas de plataforma, acima dessa profundidade. A presença desses dois tipos de água não interferiu, também, com o movimento de migração do plâncton.

Em 22 de setembro de 1960 (Fig. 2), às $12: 00$ e $16: 00 \mathrm{~h}$, as maiores densidades de plâncton encontravam-se no fundo (ao redor de $60 \%$ ), havendo na superfície, respectivamente, 15 e $11 \%$. Às 20:00 h, fundo e meia-água apre- 
sentavam a mesma densidade (40\%), sendo que na superfície a densidade aumentou para 20\%, evidenciando nitidamente o início da migração ascendente. Às $24: 00 \mathrm{~h}$, maior densidade foi encontrada à meia-água (48\%), sendo que na superfície também havia boa representação (37\%). Na camada inferior apenas $12 \%$ estavam presentes.

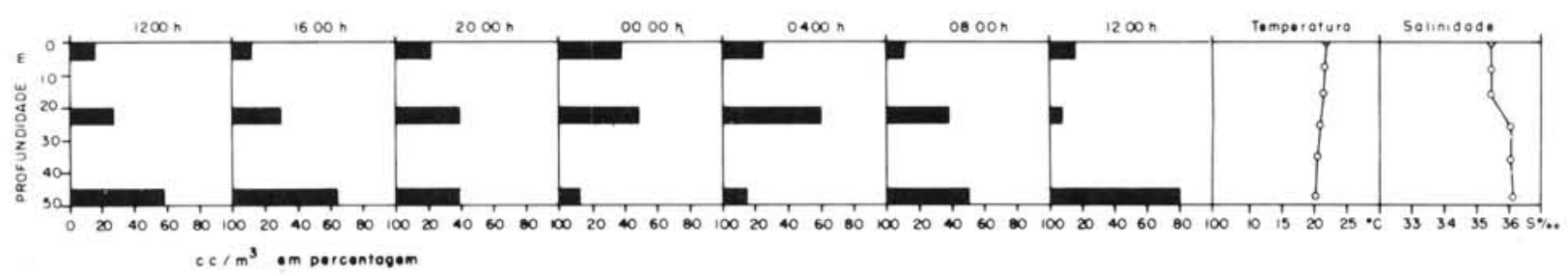

Fig. 2 - Variação na distribuição do plâncton, em percentagem. (22-23/09/60).

Esta maior densidade à meia-água, que se evidencia ainda mais nas amostras de 04:00 h, indica fortemente a presença de um fator limitando o movimento da maioria dos espécimens, que não conseguiram migrar até a superfície. Às 08:00 h, a maior densidade jā se encontrava no fundo (50\%), fato que se acentuou ainda mais às $12: 00 \mathrm{~h}(80 \%)$.

Nesta data não houve termoclina e a temperatura se manteve aproximadamente uniforme, variando de 19,7 a $22,3^{\circ} \mathrm{C}$. No entretanto, a salinidade não se manteve uniforme, mostrando uma haloclina entre 15 e $25 \mathrm{~m}$ de profundidade. Salinidades de $36 \%$ e acima estiveram presentes abaixo da haloclina, enquanto que acima da haloclina a salinidade foi ao redor de $35 \%$.

Pode-se concluir, pelos dados apresentados, que duas massas de água estiveram presentes na região: águas tropicais, abaixo de $15 \mathrm{~m}$, e águas de plataforma, acima dessa profundidade. Provavelmente as águas de plataforma, de salinidade mais baixa, constituiram o fator que limitou o movimento da maioria dos planctontes atē a superfície.

Em 21 de março de 1961 (Fig. 3), a estação foi iniciada às 16:00 h. Como também ocorreu nas outras estações, a primeira coleta foi sempre repetida no final da estação, completando um período de 24 horas de amostragens. 
Pode-se ver nesta série, que nas duas coletas de 16:00 h, uma sensível menor densidade de plâncton foi encontrada à meia-água. Isso sugere fortemente a existência de duas populações planctônicas, uma em águas superficiais, outra em āguas frias, no fundo. Às 20:00 h, vê-se que a densidade no fundo diminuiu, aumentando a de meia-água; na superfície praticamente não houve mudança. Pode-se deduzir, então, que a população de fundo começou a migrar para meia-água, o que foi ainda mais evidenciado na estação das $24: 00 \mathrm{~h}$, quando $53 \%$ estavam à meia-ägua e apenas $5 \%$ no fundo. Na superfície, a densidade continuou praticamente inalterada.

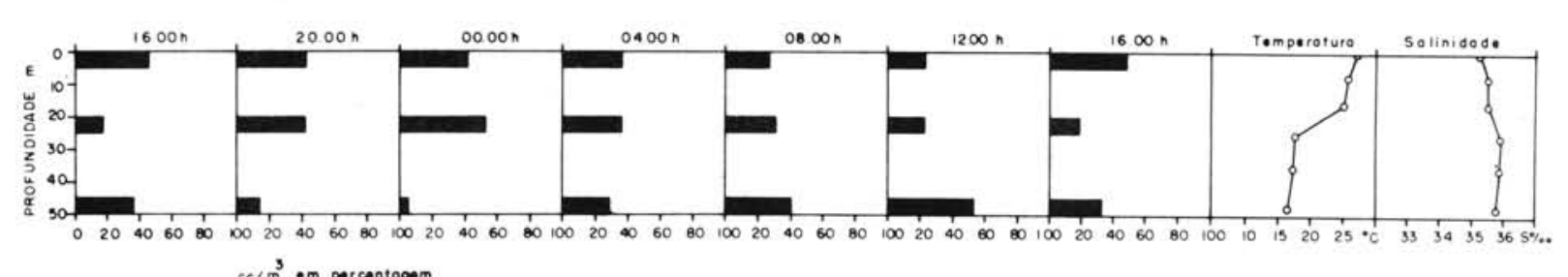

Fig. 3 - Variação na distribuição do plâncton, em percentagem. (21-22/03/61).

Às 04:00 h, jā houve um aumento da densidade na região mais profunda e uma menor densidade à meia-água (em relação à hora anterior), evidenciando que um movimento descendente $j a$ se havia iniciado. Às 12:00 h, a maioria do plâncton estava no fundo, porém a densidade na superfície ainda era acima de 20\%, indicando que um número considerável de espécimens não estava tomando parte do movimento migratörio.

Pelo exposto pode-se concluir, então, que uma migração do fundo até a meia-água foi realizada nesta data, sendo que nas regiões superficiais as densidades se mantiveram aproximadamente constantes (ao redor de $40 \%$ ). Apenas às 08:00 e 12:00 h houve uma diminuição na densidade superficial (27 e 23\%), sugerindo uma migração de aproximadamente metade desta população superficial para águas mais profundas.

Nesta data, uma pronunciada termoclina foi observada na profundidade de 15-25 m. Os limites de temperatura durante a estação foram de 16,3 e $27,0^{\circ} \mathrm{C}$. A salinidade variou de 34,91 a $35,99 \%$. Uma haloclina pouco pronunciada pôde ser notada na região da termoclina. 
Como se pode inferir dos dados temperatura-salinidade, duas massas de água estiveram presentes na região: água subtropical, abaixo de $25 \mathrm{~m}$, e água de plataforma, acima dessa profundidade.

Os dados acima analisados sugerem fortemente que a termoclina tenha constituido uma barreira para a migração de grande número dos espécimens presentes. Seria interessante comparar, quanto aos limites de tolerância às variações de temperatura, as espécies presentes nesta data com as encontradas em 8 de abril de 1960, quando a termoclina não interferiu no fenômeno (também em 9 de janeiro de 1962).

Em 6 de julho de 1961 (Fig. 4), no início da estação, às 12:00 h, a distribuição do plâncton à meia-água e fundo teve a mesma densidade $(42,6 \%)$, em relação à apenas $14,2 \%$ na superfície. No final da estação, quando se repetiram as coletas 24 horas depois, pode-se notar ainda mais claramente que embora a maior densidade se encontrasse no fundo (43\%), densidades altas estavam ainda presentes à meia-água e superfície $(30,1$ e $25,8 \%)$. Isso vem demonstrar que apenas uma parte dos organismos presentes estava migrando para o fundo, sendo que fração considerável permanecia nas camadas de meiaàgua e superfície.

Às 16:00 h não se processaram grandes mudanças nas camadas amostradas, com a distribuição sendo mais ou menos uniforme, se bem que densidade menor na camada inferior (em relação à hora precedente), sugere já ter sido iniciado o movimento ascendente dos organismos nela presentes. As 20:00 h a maior densidade foi nítida à meia-água, embora quantidade apreciāvel também estivesse presente no fundo. Esse quadro repetiu-se às 24:00 h, porém já aparece modificado às 04:00 h, quando a maior densidade se encontra no fundo.

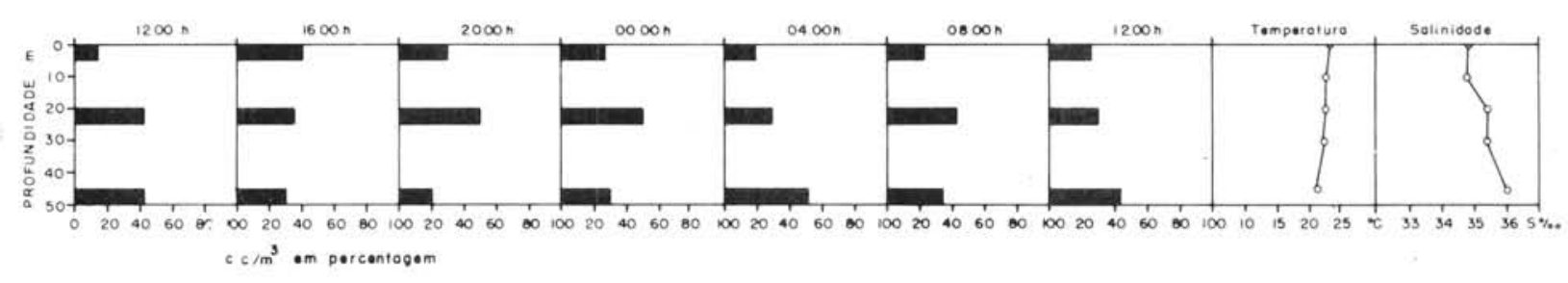

Fig. 4 - Variação na distribuição do plâncton, em percentagem. (06-07/07/61). 
Pode-se concluir, então, que pelo menos parte dos indivíduos presentes realizou uma migração até a meia-água nas primeiras horas da noite, começando a descer depois das 24:00 h. A interferência de algum fator limitando o movimento ascendente até a superfície pode aqui também ser registrada. Às 08:00 h o quadro não é muito típico, pois mais uma vez se nota uma densidade maior à meia-água, sugerindo novamente pequena ascendência de alguns organismos. A presença de ondas internas foi assinalada na região por Johannessen (1967). Isso, conjugado a outros fatores, talvez possa explicar esses pequenos deslocamentos ocorridos ocasionalmente.

Nesta data $(06 / 07 / 1961)$, a temperatura manteve-se uniforme, variando de 20,84 a $23,20^{\circ}$ C. Esta estação e a de 22 de setembro de 1960 foram as duas estudadas, da série de sete, que não apresentaram termoclina. No entretanto, ambas diferem sensivelmente nas condições de salinidade, e conseqüentemente nos tipos de massa de água.

A salinidade na presente estação variou de 34,76 a $36,13 \%$. Salinidades abaixo de $35 \%$ foram registradas em todas as coletas até $20 \mathrm{~m}$. Abaixo desta profundidade, salinidades maiores que 35 e até ao redor de $36 \%$ foram obtidas. Isso demonstra que duas massas de água estiveram presentes na região: àguas costeiras, até $20 \mathrm{~m}$ de profundidade, e, abaixo, águas de plataforma (ocasionalmente misturadas com a tropica1).

Há forte indicação de que o fator que limitou o movimento ascendente do plâncton, na camada dos $20 \mathrm{~m}$, foi a presença de água costeira de baixa salinidade. As densidades relativamente altas encontradas repetidamente nas camadas de meia-água, mesmo às $12: 00 \mathrm{~h}$, sugerem a existência de populações vivendo na zona de mistura das duas massas de água presentes na data da realização das estações.

Em 7 de novembro de 1961 (Fig. 5), encontrou-se exatamente o inverso do que seria de esperar no caso da migração vertical diária. A maior concentração na superfície, em relação às outras horas de coleta, ocorreu às $12: 00 \mathrm{~h}$, enquanto nas horas noturnas houve a maior abundância de plâncton na camada de fundo.

Os parâmetros medidos absolutamente não são suficientes para a explicação desta ocorrência. Enright \& Hamner (1967), estudando em laboratório a 
migração vertical de inúmeras espécies, verificaram que algumas realizavam normalmente um movimento diärio do tipo encontrado aqui. Esta talvez não seja a explicação para o caso, porém constitui mais um exemplo de variável que pode influir na migração vertical, principalmente quando se considera plâncton total.

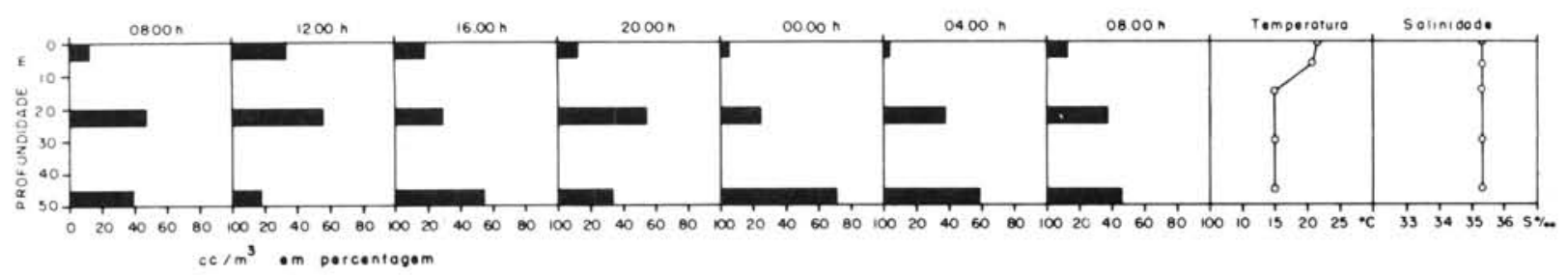

Fig. 5 - Variação na distribuição do plâncton, em percentagem. (07-08/11/61).

Nesta data, a temperatura variou de 15,05 a $22,00^{\circ} \mathrm{C}$, e uma bem marcada termoclina esteve presente entre 15 e $7 \mathrm{~m}$. Os limites de salinidade foram 35,36 e 35,72 \% Águas de plataforma ocorreram sobre a termoclina, e subtropical nas camadas abaixo. Condições hidrográficas semelhantes ocorreram em 8 de abril de 1960 e 21 de março de 1961, porém nestas datas não houve inversão do quadro migratório típico.

Em 9 de janeiro de 1962 (Fig. 6), às 16:00 h, a maior densidade de plâncton encontrava-se no fundo $(55,3 \%)$, com $30,1 \%$ à meia-água e $14,6 \%$ na superfície. Às $20: 00 \mathrm{~h}$ o quadro apresentou-se totalmente invertido, com $58,8 \%$ do plâncton na superfície e apenas $12 \%$ no fundo. Este fato vem demonstrar que nas horas crepusculares houve intensa migração dos organismos planctônicos para as camadas superiores, perfazendo uma distância de quase 50 m numa média horária que pode ser considerada bastante grande, em relação ao pequeno tamanho dos animais.

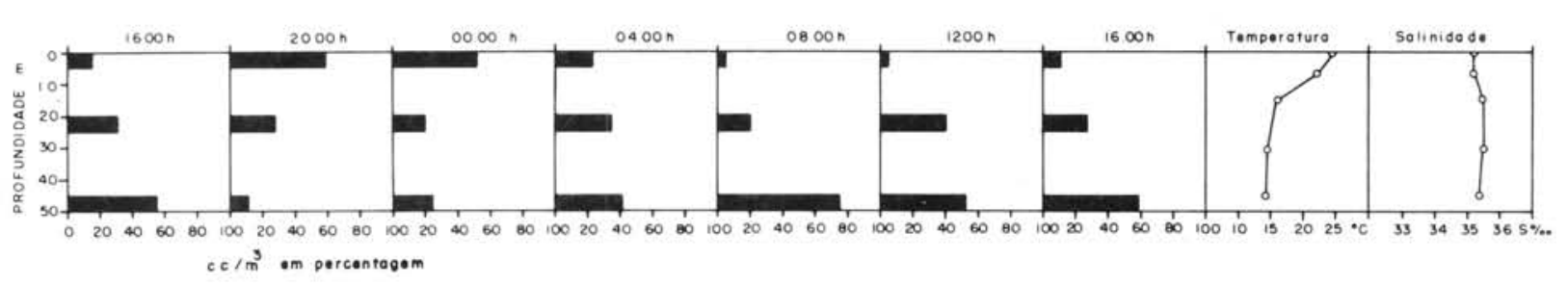

Fig. 6 - Variação na distribuição do plâncton, em percentagem. (09-10/01/62). 
Hardy \& Bainbridge (1954), usando uma engenhosa roda, na qual colocavam plâncton, puderam calcular a velocidade de algumas espécies de copépodes (pertencentes a gêneros comuns nas costas sul brasileiras), verificando que Calanus pode se locomover para cima a $15 \mathrm{~m} /$ hora, Centropages pode alcançar o dobro dessa velocidade e Acartia, apesar do pequeno tamanho, pode alcançar velocidade de $9 \mathrm{~m} /$ hora.

Às 24:00 h um movimento descendente já teve início, pois a densidade na superfície é um pouco menor e a do fundo um pouco maior, quando comparadas com a da hora anterior. Às 04:00 h jā há maior densidade no fundo, embora as concentrações na superfície e à meia-água ainda sejam relativamente grandes. Esse início de descida antes do amanhecer como já ocorreu em 21/03/1961 e 06/08/1961, leva a supor que fatores outros que a luz tenham interferido para esse movimento. As 08:00 h a grande densidade estava no fundo (75\%) e apenas $5 \%$ na superfície. Às $12: 00 \mathrm{~h}$ jā pode ser observado um aumento na densidade à meia-água (quando comparada com a coleta das 08:00 h), e uma correspondente diminuição na densidade da camada do fundo. Este fato já indica - início de uma migração ascendente mesmo a essa hora do dia. Às 16:00 h esse quadro se tornou nítido, pois embora na camada profunda a densidade quase não se tenha alterado, à meia-água houve uma diminuição e na superfície um aumento (quando comparadas à hora precedente de coleta).

Esta estação diferiu das demais pela defasagem do ciclo migratório em relação às zero e $12: 00 \mathrm{~h}$. Entretanto, em toda a série, foi o exemplo mais típico e marcante do movimento migracional do plâncton. Os quadros de 20:00 e 08:00 h representam as figuras mais acentuadas de uma inversão na distribuição do plâncton noturno e diurno.

As condições hidrográficas nesta data caracterizaram-se pela presença de pronunciada termoclina entre 15 e $7 \mathrm{~m}$. Os limites de temperatura foram 14,09 e $25,20^{\circ}$ C. A salinidade variou de 35,17 a $35,53 \%$. Duas massas de água estiveram presentes: água subtropical abaixo da termoclina e águas de plataforma nas regiões superficiais.

Quanto as condições hidrográficas e época do ano, esta estação pode ser comparada às realizadas em 8 de abril de 1960 e 21 de março de 1961. Quanto à primeira, ela se assemelha pela termoclina não ter funcionado como uma barreira para o movimento migratório e pela maior densidade do plâncton, às 
$20: 00 \mathrm{~h}$, nas camadas superficiais. Quanto à segunda, o resultado do movimento migratório foi completamente diferente, desde que um efeito da termoclina sobre a migração foi evidenciado a 21 de março de 1961. Isto indica a complexidade do fenômeno e a importância das condições biōticas, além das abiōticas, na migração.

Em 28 de novembro de 1962 (Fig. 7), às zero e 04:00 h, não houve diferença sensível na distribuição do plâncton nas camadas amostradas. Às 08:00 h houve uma diminuição da densidade na superfície e um aumento da mesma à meia-água e fundo (quando comparadas à hora de coleta anterior), o que sugere que nas horas do amanhecer houve um começo de migração descendente. Às $12: 00 \mathrm{~h}$ a maior densidade foi no fundo (46\%), porēm à meia-água e superfície densidades de 29 e $23 \%$ foram registradas, indicando que apenas parte do total de organismos presentes estavam tomando parte no movimento migracional.

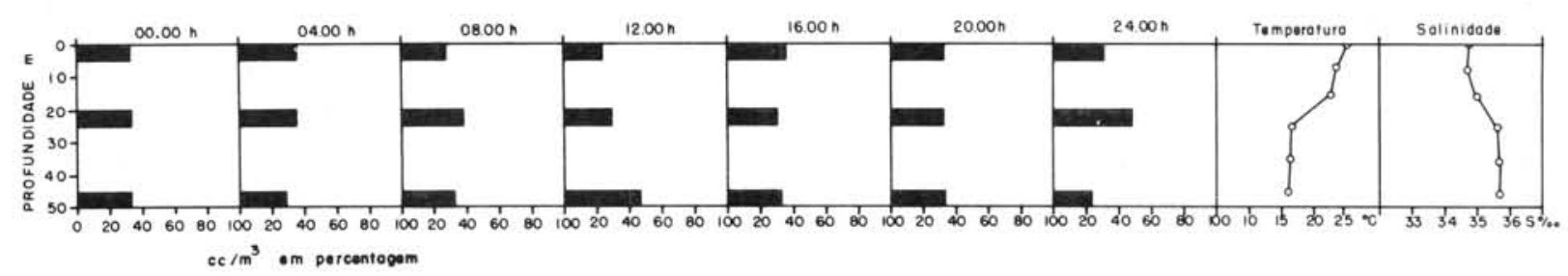

Fig. 7 - Variação na distribuição do plâncton, em percentagem. (28/11/62).

Às $16: 00 \mathrm{~h}$ novamente pode-se considerar a distribuição uniforme (na superfície a densidade foi ligeiramente maior), repetindo-se este quadro às $20: 00 \mathrm{~h}$. As coletas realizadas às $24: 00 \mathrm{~h}$ mostraram maior densidade à meiaágua e menor no fundo, quando comparadas com a hora anterior, o que sugere que embora na noite anterior o plâncton tivesse se mantido uniformemente distribuido, 24 horas depois houve uma migração de organismos da camada de fundo para a meia-água. Na superfície, durante as horas noturnas, as densidades foram relativamente constantes (32 a 35\%). A migração vertical diāria nesta estação foi pouco nítida, com porcentagens altas e aproximadas nos três níveis. Somente pequenas oscilações indicam o movimento.

Dados de temperatura mostraram uma nítida termoclina entre $15-25 \mathrm{~m}$. As variações de temperatura foram de 16,33 a $26,00^{\circ} \mathrm{C}$. A salinidade variou de 
Bolm Inst. oceanogr., S Paulo, 25, 1976

34,58 a $35,86 \%$. Salinidades abaixo de $35 \%$ estavam presentes acima de $15 \mathrm{~m}$, enquanto que salinidades maiores que $35 \%$ foram encontradas abaixo dessa profundidade. Uma nitida haloclina pode ser observada na mesma região da termoclina.

Duas massas de água estiveram presentes: subtropical (abaixo de $15 \mathrm{~m}$ ) e costeira (acima de $15 \mathrm{~m}$ ). A presença desta ūltima massa de āgua foi também registrada em 6 de julho de 1961, acima de $10 \mathrm{~m}$. Nestas duas estações a presença de densidades relativamente grandes e constantes de plâncton na superfície foram observadas durante todas as horas, sugerindo que massas de água diferentes nas regiões mais profundas limitariam o movimento descendente dos organismos presentes na massa de água costeira.

\section{DISCUSSÃO}

Embora a migração vertical do plâncton seja um fenômeno bastante generalizado, como jā foi salientado na introdução, apresenta características prōprias nas diferentes äreas. Os presentes dados, além de serem os primeiros para águas brasileiras, também constituem um dos poucos em regiões sobre a plataforma, pois a grande maioria dos trabalhos existentes se referem a āguas oceânicas.

Em todas as estações ocupadas ao largo de Santos, durante os três anos, ocorreu migração vertical diāria. Esta, no entretanto, apresentou diferenças observando-se os seguintes padrões: a) migração pronunciada, com a grande maioria dos indivíduos percorrendo toda a coluna, desde o fundo até a superfície nas horas crespusculares, e voltando para o fundo ao amanhecer; b) migração pouco pronunciada, mantendo-se a densidade nos três níveis, apenas ligeiramente modificada no decorrer do período; c) migração interrompida à meia-água, perfazendo então a maioria dos planctontes apenas metade da coluna de água estudada; e d) um último tipo, que ocorreu apenas uma vez, migração vertical atípica, na qual a maioria dos animais esteve próxima ao fundo nas horas noturnas e nas camadas mais superficiais durante o dia. 
0 movimento ascendente e a descida dos organismos nem sempre coincidiu com as horas de maior variação de intensidade luminosa (amanhecer e anoitecer), indicando que nem sempre a luz foi o principal fator envolvido no fenômeno. A termoclina atuou como um fator limitando o movimento migracional em apenas uma das cinco estações onde esteve presente. Água costeira ocorreu na superfície em duas estações, com grandes densidades de plâncton durante todo o período de 24 horas; a maioria dos organismos nela presentes, não penetrou, no seu movimento descendente, nas águas de maior salinidade das camadas inferiores (ägua de plataforma e subtropical).

Na região estudada, durante os meses mais frios, as condições hidrográficas se tornam mais homogêneas quanto à temperatura, mas o movimento migracional pode ser limitado em sua extensão pela presença de massa de água de diferente salinidade, como ocorreu a 6 de julho de 1961. De setembro a dezembro, uma estratificação térmica é geralmente formada e uma bem marcada termoclina é estabelecida no verão. No entretanto, uma acentuada migração pode ocorrer, como se deu a 9 de janeiro de 1962, ou o movimento pode ser apenas do fundo até meia-água, como em 21 de março de 1961.

Uma verdadeira relação ecológica das migrações estudadas só é possíve1 com o estudo detalhado das espécies presentes, como foi feito para os Chaetognatha (Almeida Prado, 1968), Copepoda (Björnberg, 1969) e Hydromedusae (Moreira, 1973). Espécies relativamente grandes e ocorrendo em grande abundância, como por exemplo a medusa Liriope tetraphyzla, têm uma marcada influência nos resultados de plâncton total. Estas medusas, sendo euritérmicas e migrando facilmente através das termoclinas, pouco deixaram evidenciar da importância da temperatura como fator limitando o movimento dos animais, quando considerados de uma maneira geral. O que é importante, no presente trabalho, é a conclusão de que, na região estudada, a migração vertical do plâncton não segue os mesmos padrões nas diferentes épocas do ano e nem pode ser diretamente correlacionada com as condições oceanográficas predominantes na região. Este fato é básico para futuros planejamentos de estudos de distribuição e ecologia ao largo de Santos, assim como na interpretação dos resultados obtidos de amostras jā coletadas nos estudos de indicadores. 


\section{RESUMO}

Vārias estações foram ocupadas ao largo de Santos, durante os anos de 1960, 1961 e 1962, com a finalidade do estudo da migração vertical diāria do plâncton, assim como sua relação com os parâmetros temperatura, salinidade e massas de água. Os quadros gerais do movimento vertical variaram nas diferentes datas. Demonstrou-se que a luz nem sempre pôde ser considerada como o principal fator envolvido na migração. A termoclina atuou como um fator limitando o movimento em apenas uma, das cinco estações onde esteve presente. Em estações onde ocorreram massas de água de diferentes limites de salinidade, a migração dos zooplanctontes ocorreu em geral acima ou abaixo da região de encontro dessas massas de água, independente da presença ou não de termoclina. Concluiu-se que, na região onde os estudos foram feitos, a migração diāria do plâncton se apresenta bastante diversificada e não pode ser diretamente relacionada a diferentes épocas do ano ou condições oceanogräficas predominantes na região. Este fato deve ser levado em conta em futuros estudos de distribuição e ecologia na região, assim como, nos resultados obtidos nos estudos de indicadores planctônicos.

\section{SUMMARY}

Several stations were occupied off the coast of Santos, during the years of 1960, 1961 and 1962, with the purpose of studying the diurnal vertical migration of the plankton, as well as its relation with temperature, salinity and water masses. The general features of the vertical movement varied in the different data. The light was not always the major factor influencing the migration. The thermocline was a limiting factor only in one of the five stations where it was present. In stations where water masses with different salinities were present, the migration occurred above or under the haloclines, independently of the presence or not of thermocline. It was concluded that, in the region where these studies were done, 
the diurnal vertical migration of plankton is quite diversified and it cannot be directly related to different seasons or oceanographic parameters. This fact must be considered in future studies on distribution and ecology in the region, as well as, in the results obtained from plankton indicator studies.

\section{AGRADECIMENTOS}

Quando este trabalho foi realizado, a autora pertencia ao quadro do Instituto Oceanográfico da Universidade de São Paulo, ao qual agradece todas as facilidades proporcionadas para sua realização, principalmente nas pessoas do Dr. Ingvar Emílsson e Dra. Marta Vannucci, que a incentivaram e auxiliaram com preciosas sugestões.

De um modo muito especial quero agradecer a colaboração do Mestre do barco "Emília" naquela época, Sr. Benedito Quintero, e também aos Srs. Clarimundo de Jesus, Wilson Ribas e Hermenegildo Santana, que além de fazerem com que fosse possíve1 a realização de todas as estações, ainda conseguiram, com sua amizade e bom humor, tornar agradāveis aqueles longos dias e noites de trabalhos ininterruptos.

\section{B IBLIOGRAF I A}

ALMEIDA PRADO, M. S. 1961. Distribuição dos Chaetognatha no Atlântico Sul Ocidental. Bolm Inst. oceanogr., S Paulo, 11:15-49.

1968. Distribution and annual occurrence of Chaetognatha off Cananéia and Santos coast (São Paulo, Brazil). Bolm Inst. oceanogr., S Paulo, 17:33-55. 
BANSE, K. 1964. On the vertical distribution of zooplankton in the sea. In: Sears, M., ed. - Progress in oceanography. New York, Macmillan, $2: 53-125$.

BIGELOW, H. B. \& SEARS, M. 1939. Studies of the waters of the continental shelf, Cape Cod to Chesapeake Bay. III. A volumetric study of the zooplankton. Mem. Mus. comp. Zool. Harv., 54:183-378.

BJÖRNBERG, T. K. S. 1963. On the marine free-living copepods off Brazil. Bolm Inst. oceanogr., S Paulo, 13(1):3-142.

1969. Distribution of planktonic copepods in shelf waters off Santos. Intern. Symp. Fert. Sea, S Paulo, December 1-6, Abstracts (19).

\& WILBUR, K. M. $1968 . \quad$ Copepod phototaxis and vertical migration influenced by xanthene dyes. Biol. Bull. mar. biol. Lab., Woods Hole, 134(3):398-410.

BOGOROV, V. G. 1946. Peculiarities of diurnal vertical migrations of zooplankton in polar seas. J. mar. Res., 6(1):25-32.

CLARKE, G. L. 1933. Diurnal migration of plankton in the Gulf of Maine and its correlation with changes in submarine irradiation. Biol. Bu11. mar. biol. Lab., Woods Hole, 65:402-436.

CUSHING, D. H. 1951. The vertical migration of planktonic Crustacea. Bio1. Rev., $26: 158-192$.

CUVIER, G. 1817. Le règne animale. Paris, 17, 278 p.

DAVID, P. M. 1961. The influence of vertical migration on speciation in the oceanic plankton. Syst. Zool., 10(1):10-15.

EMÍLSSON, I. 1959. Alguns aspectos físicos e químicos das águas marinhas brasileiras. Ciênc. Cult., S Paulo, 11(2):44-54.

1961. The shelf and coastal waters off southern Brazil. Bolm Inst. oceanogr., S Paulo, 11(2):101-112.

ENRIGHT, J. T. \& HAMNER, W. M. 1967. Vertical diurnal migration and endogenous rhythmicity. Science, N. Y., 157(3791):937-941.

ESTERLY, C. 0. 1917. Occurrence of a rhythm in the geotropism of two species of plankton copepods when certain recurring external conditions are absent. Univ. Calif. Publs Zool., 16:393-400.

FORNERIS, L. 1965. Appendicularian species groups and southern Brazil water masses. Bolm Inst. oceanogr., S Paulo, 14:53-113.

HARDY, A. C. 1956. The open sea, its natural history: the world of plankton. London, Collins, 355 p. 
HARDY, A. C. \& BAINBRIDGE, R. 1954. Experimental observations on vertical migrations of plankton animals. J. mar. biol. Ass. U. K., 33: 409-448.

\& GUNTHER, E. R. 1936. Plankton of the South Georgia whaling grounds and adjacent waters, 1926-1927. 'Discovery' Rep., 11: $1-456$.

HURE, J. 1955. Distribution annuelle verticale du zooplancton sur une station de $1^{\circ}$ Adriatique meridionale. Acta adriat., 7:1-72.

JOHANNESSEN, O.M. 1967. Note on the diurnal temperature observations off the coast of Santos, Brazil. Contrções Inst. oceanogr. Univ.S Paulo, sér. Ocean. fís., (9):1-7.

JOHNSON, W. H. 1938. Effect of light on vertical movements of Acartia clausi (Giesbrecht). Biol. Bull. mar. biol. Lab., Woods Hole, 75:106-118.

KIKUCHI, K. 1930. Diurnal migration of plankton Crustacea. Q. Rev. Biol., 5:189-206.

KING, J. E. \& HIDA, T. S. 1954. Variations in zooplankton abundance in Hawaiian waters 1950-52. Spec. scient. Rep. U. S. Fish Wildl. Serv., 118:1-66.

1957. Zooplankton abundance in the Central Pacific. II. Fishery Bull. Fish Wildl. Serv. U. S., 57:365-395.

LEEGAND, M. 1958. Étude sommaire des variations quantitatives diurnes du zooplancton autour de la Nouvelle Calédonie. Rapp. scient. Inst. fr. Océanie, Sect. Océanogr., 6:1-42.

MCALLISTER, C. D. 1961. Zooplankton studies at ocean weather station "P" in the northern Pacific Ocean. J. Fish. Res. Bd Can., 18(1):1-29.

MOORE, H. B. \& BAUER, G. C. 1960. An analysis of the relation of the vertical distribution of three copepods to environmental conditions. Bull. mar. Sci. Gulf Caribb., 10(4):430-443.

\& CORWIN, E. G. 1956. The effect of temperature, illumination and pressure on the vertical distribution of zooplankton. Bull. mar. Sci. Gulf Caribb., 6(4):273-287.

MOREIRA, G. S. 1973. On the diurnal vertical migration of Hydromedusae off Santos, Brazil. Publs Seto mar. bio1. Lab., 20:537-566.

MURRAY, J. 1885. Narrative of the cruise. Rep. scient. Results Voyage H.M.S. "Challenger", 1873-76, 1(1):1-509.

RUSSEL, F. S. 1925-1934. The vertical distribution of marine macroplankton I-XII. J. mar. biol. Ass. U. K., 13-19. 
TAVARES, D. Q. 1967. Occurrence of doliolids and salps during the years 1958, 1959 and 1960 off the São Paulo coast. Bolm Inst. oceanogr., S Paulo, 16:87-97.

TUNDISI, J. G., KUTNER, M. B. \& TUNDISI, T. M. 1969. Plankton studies in a mangrove environment. VIII. Primary production, standing-stock of phyto and zooplankton and some environmental factors. Intern. Symp. Fert. Sea, S Paulo, December 1-6. Abstracts (39).

VANNUCCI, M. 1957. On Brazilian Hydromedusae and their distribution in relation to different water masses. Bolm Inst. oceanogr., S Paulo, $8: 23-109$.

1963. On the ecology of Brazilian medusae at $25^{\circ}$ Lat. S. Bolm Inst. oceanogr., S Paulo, 13:143-184.

VINOGRADOV, M. E. 1970. Vertical distribution of the oceanic zooplankton. Jerusalem, Israel Program for Scientific Translation, 339 p.

WATERMAN, T. R., NUNNEMACKER, R. F., CHACE, F. A. \& CLARKE, G. L. 1939. Diurnal vertical migration of deep-water plankton. Biol. Bull. mar. biol. Lab., Woods Hole, 76:256-272.

WORTHINGTON, E. B. 1931. Vertical movements of freshwater macroplankton. Int. Revue ges. Hydrobiol. Hydrogr., 25:394-436.

(Recebido em 24/outubro/1974) 